\title{
Measuring Thermal Mass of Sustainable Concrete Mixes
}

\author{
Omer Damdelen, Costas Georgopoulos and Mukesh Limbachiya \\ School of Engineering, Faculty of Science, Engineering and Computing, Kingston University, London KT1 2EE, UK
}

\begin{abstract}
Thermal mass is currently evaluated with "admittance" which is the ability of the element to exchange heat with the environment and is based on specific heat capacity, thermal conductivity and density. The aim of this study is to evaluate the effect of thermal properties namely, density, specific heat capacity and thermal conductivity on thermal mass. The objective of the study is to carry out laboratory experiments by measuring such thermal properties of concrete mixes with various percentages of GGBS (ground granulated blast furnace slag), PFA (pulverized fuel ash), and SF (silica fume) and RCA (recycled coarse aggregates). The results obtained from these tests would contribute to the evaluation of how such thermal properties influence the thermal admittance and hence the thermal mass performance of sustainable concrete elements in a building system.
\end{abstract}

Key words: Thermal mass, thermal admittance, thermal properties, sustainable concrete.

\section{Introduction}

One of the challenges in sustainable development is to optimize the energy efficiency of buildings during their lifespan. Modern concretes offer both low embodied $\mathrm{CO}_{2}$ with the use of cement-replacements and recycled aggregates and reduced operational $\mathrm{CO}_{2}$ with the intrinsic property called "thermal mass" that reduces the risk of overheating in the summer and provides passive heating in the winter [1]. Sustainable construction is becoming more popular as this sector corresponds to the world changing needs. Variations concerning global warming are the most important factor in which construction industry is exposed to. The purpose of those variations is to increase the life of the residence by lowering $\mathrm{CO}_{2}$ emissions and to increase the use of natural resources. Environmental problems created in construction industry can be overwhelmed by decreasing both embodied and total energy usage for the construction products. Energy consumption figures in European buildings are increasing every year due to increase in air-conditioning and heating usages as a result of greater standards of living [2]. Examination of thermal

Corresponding author: Omer Damdelen, Ph.D., research field: thermal mass in sustainable concrete construction. E-mails: K0838912@kingston.ac.uk. mass can be used to prevent or minimize temperature swings in the building and can also be used to eliminate the need for energy consuming for air conditioning systems.

Thermal mass which is also called thermal inertia is related to the storage material. Storage material is the mass of the building including walls, partitions, ceilings and floors where all have high heat capacity. The most important factors associated to heat storage (i.e., thermal mass) are thermal conductivity $(\lambda)$, specific heat capacity $(c)$ and the density $(\rho)$ of the concrete.

Thermal mass can explain the ability of the concrete to store the transferred heat/cool. Thermal mass can be determined by thermal diffusivity $(\alpha)$ of the building material that can be expressed as;

$$
\alpha=\frac{\lambda}{c \rho}
$$

The higher the $\lambda$ and the lower the product of $\rho$ and $c$, the higher the heat storage capability of the material. As a conclusion, the usefulness of thermal storage depends on several parameters, such as materials' properties, the exposed surface area, the thickness of the storing elements and its location and orientation within the building (as an external or an internal partition) [3].

The storage capacity of the slab is determined by 
the thickness of the penetration depth. If a building has a natural ventilation system with a concrete of thin penetration depth (i.e., $50 \mathrm{~mm} \times 75 \mathrm{~mm}$ ), it is operationally efficient for heat transfer and storage.

Daily temperature cycle which is called sinusoidal cycle has a period of 24 hours. The slab reacts to variations occurred in this daily cycle. According to CIBSE Guide (1999), exchange of heat and cool over the cycle is measured by thermal admittance that can be defined as Ref. [4];

$$
Y=\frac{Q \text { swing }}{\text { Tswing }}
$$

From the above definition of thermal admittance, it can be resulted that for a given temperature variation, heat/cool load that can be absorbed by the slab has a direct relationship with the thermal admittance.

Since heavy materials such as concrete, brick or stone have a large, internal exposed capacity, those materials were storing greater part of the daily energy cycle. High admittance of those materials results in small temperature swing in the room. The unit for admittance $(Y)$ is $\mathrm{W} / \mathrm{m}^{2} \cdot \mathrm{K}$. Admittance values for several construction components are given in CIBSE Guide section A3 [5].

Materials having a high density will have a high thermal conductivity and therefore these materials are classified as good for heat storage.

The aim of the admittance method is predicting indoor temperature and by this way, evaluating peak environmental temperature for any proposed building. Details about the technique of this method can be found from CIBSE guide, section A8 [6].

Performance of the system is highly affected by thermo-physical properties of the materials. Therefore, high density in a building material indicates high thermal conductivity such as having a building with poor thermal resistance. On the other hand, insulation materials have a low thermal conductivity and high thermal resistance. This indicates that those materials can be used for insulation purposes but not for heating. Efficient heat storage material should have high density, thermal capacity and thermal conductivity $[7,8]$.

\section{Research Methodology and Experimental}

\subsection{Research Methodology}

By using each cement replacement material separately, such as SF (silica fume), PFA (pulverized fuel ash), and GGBS (Ground granulated blasted slag) will be illuminating the factor that how these cement replacement materials may affect the thermal properties of concrete.

\subsection{Experimental Design}

\subsubsection{Preparation of Mixes}

The mixes used in this study are described in Table 1. There are eight different specimens that can be classified in into two sections, namely, coarse aggregate and recycled coarse aggregate concretes.

\subsubsection{Materials}

The following materials were applied to produce concrete mixes.

- OPC (ordinary Portland cement): A single source (Lafarge cement) of Class $52.5 \mathrm{~N}$ OPC confirming to BS EN 197-1 was applied;

- GGBS (ground granulated blast-furnace slag): A single source (Civil-Marine) of GGBS confirming to BS 6699/BS EN 197-1 was applied;

- SF (silica fume): A single batch of silica fume confirming to EN 13263-1 was applied;

Table 1 The mixes prepared for the measurement of thermal properties.

\begin{tabular}{|c|c|}
\hline Mix No. & Definition \\
\hline A1 & $100 \%$ coarse aggregate OPC concrete \\
\hline A2 & $100 \%$ coarse aggregate OPC/GGBS $(45 \%)$ concrete \\
\hline A6 & $100 \%$ coarse aggregate OPC/PFA $(20 \%)$ concrete \\
\hline A8 & $100 \%$ Coarse Aggregate OPC/SF (10\%) concrete \\
\hline B1 & Recycled Coarse Aggregate (30\%) OPC concrete \\
\hline B2 & $\begin{array}{l}\text { Recycled coarse aggregate }(30 \%) \text { OPC/GGBS } \\
(45 \%) \text { concrete }\end{array}$ \\
\hline B6 & $\begin{array}{l}\text { Recycled coarse aggregate }(30 \%) \text { OPC/PFA }(20 \%) \\
\text { concrete }\end{array}$ \\
\hline B8 & $\begin{array}{l}\text { Recycled coarse aggregate (30\%) OPC/SF }(10 \%) \\
\text { concrete }\end{array}$ \\
\hline
\end{tabular}


- PFA is used according to BS-EN 450-1 (2012). PFA used in the UK is classified as CEM IV according to BS EN 197-1 (2011);

- Graded natural sand with a maximum particle size of $5 \mathrm{~mm}$ and complying with the requirements of BS EN 12620-1 (2009) were used as fine aggregate in the concrete mixes;

- Two types of coarse aggregate will be used in the study, NA (natural aggregate) and RCA (recycled coarse aggregate). Natural aggregate used was Thames Valley gravel with a size fraction between 20 $\mathrm{mm}$ and $5 \mathrm{~mm}$. The used RCA was obtained from processing concrete debris from demolished concrete structures. The size of fraction of the RCA is between $20 \mathrm{~mm}$ and $5 \mathrm{~mm}$ (the supplier for fine and coarse aggregates is Day Company (BS EN 2620:2002 Classifying Aggregates).

\subsubsection{Mix Proportions}

Tables 2 and 3 give the mix proportions for the test concrete mixes. All of the mixes applied in the study were designed to have a slump of $60-180 \mathrm{~mm}$. which is the range of acceptable slumps according to EN 206-1. As well as this, the range of the compacting factor of fresh concrete mixes was determined. All the mixes applied in the study were designed to have a compacting factor of $0-3 \mathrm{~s}$.

\section{Sample of Testing Concrete Mixes}

From this study, it is concluded that understanding the thermal properties by performing such concrete tests is vital. The most commonly used tests in this research are described as follows.

\subsection{Specific Heat Capacity}

Specific heat capacity is investigated as a thermal property of the concrete, so that it can be determined how much mass is needed per unit for one unit increase in temperature of the sample. By this way, specific heat capacity can be used to explain association between heat and temperature variation. Specific heat capacity is measured by performing an experimental procedure in an insulated box.
Table 2 Mix proportions for natural aggregate concrete mixes.

\begin{tabular}{|c|c|c|c|c|c|}
\hline \multirow{2}{*}{\multicolumn{2}{|c|}{ Mix No. }} & \multicolumn{4}{|c|}{ Constituent proportions $\left(\mathrm{kg} / \mathrm{m}^{3}\right)$} \\
\hline & & \multirow{2}{*}{$\begin{array}{l}\text { A1 } \\
85\end{array}$} & \multirow{2}{*}{$\begin{array}{l}\mathrm{A} 2 \\
85\end{array}$} & \multirow{2}{*}{$\begin{array}{l}\text { A6 } \\
84\end{array}$} & \multirow{2}{*}{$\begin{array}{l}\text { A8 } \\
85\end{array}$} \\
\hline FA & & & & & \\
\hline NA & & 180 & 180 & 189 & 180 \\
\hline RCA & & - & - & - & - \\
\hline $\mathrm{OPC}$ & & 50 & 27.5 & 43 & 45 \\
\hline \multirow{3}{*}{ CRM } & GGBS & - & 22.5 & - & - \\
\hline & PFA & - & - & 11 & - \\
\hline & SF & - & - & - & 5.0 \\
\hline \multicolumn{2}{|l|}{$\mathrm{FA} / \mathrm{CA}$} & 0.47 & 0.47 & 0.47 & 0.47 \\
\hline \multicolumn{2}{|l|}{$\mathrm{W} / \mathrm{C}$} & 0.57 & 0.57 & 0.49 & 0.57 \\
\hline
\end{tabular}

Table 3 Mix proportions for recycled coarse aggregate concrete mixes.

\begin{tabular}{|c|c|c|c|c|c|}
\hline \multirow{2}{*}{\multicolumn{2}{|c|}{ Mix No. }} & \multicolumn{4}{|c|}{ Constituent proportions $\left(\mathrm{kg} / \mathrm{m}^{3}\right)$} \\
\hline & & \multirow{2}{*}{$\frac{B 1}{87}$} & \multirow{2}{*}{$\frac{\mathrm{B} 2}{87}$} & \multirow{2}{*}{$\frac{\mathrm{B} 6}{87}$} & \multirow{2}{*}{$\begin{array}{l}\text { B8 } \\
87\end{array}$} \\
\hline PFA & & & & & \\
\hline NA & & 123 & 123 & 122 & 123 \\
\hline $\mathrm{RCA}$ & & 53 & 53 & 52 & 53 \\
\hline OPC & & 50 & 28 & 43 & 45 \\
\hline \multirow{3}{*}{ CRM } & GGBS & - & 22.5 & - & - \\
\hline & PFA & - & - & 11 & - \\
\hline & SF & - & - & - & 5.0 \\
\hline \multicolumn{2}{|l|}{$\mathrm{FA} / \mathrm{CA}$} & 0.49 & 0.49 & 0.49 & 0.47 \\
\hline \multicolumn{2}{|c|}{$\mathrm{W} / \mathrm{C}$} & 0.59 & 0.59 & 0.51 & 0.57 \\
\hline
\end{tabular}

The following steps should be attained one day before carrying out the test. Oven is pre-heated at suitable temperature (i.e., $100{ }^{\circ} \mathrm{C} \pm 5{ }^{\circ} \mathrm{C}$ ) and the sample is placed in this pre-heated oven in order to reach a constant temperature. Since the same stainless bucket is used for all specific heat capacity experiments, mass of the stainless steel bucket is constant and it is measured only once. Then, approximately half of the bucket is filled with water and the total mass of the stainless bucket with water is measured.

After that, the mass of water can be determined by subtracting the constant mass of stainless bucket from the total mass of bucket with water. Bucket with half-filled water is placed inside the insulated box. During the overnight stay, the front of the insulated box is kept open in order to achieve constant temperature.

After this overnight stay, it connects the thermometer to the bucket with water to check the temperature. If the temperature is constant, this means 
that the bucket with water is now ready to be used for testing. However, before the start of testing, weight of the bucket with water should be re-measured to aware of any variations in mass of water due to evaporation that might occur during overnight stay. Three different thermometers are placed inside the insulated box to measure the temperature of the concrete, water and air respectively during the testing procedure.

Beside of this, relative humidity is measured to estimate the mass of the dry air. This apparatus is specifically designed for this research in Kingston University. It can be seen from Fig. 1.

Observed values from the three different thermometers are used to evaluate the value for specific heat capacity by using the formula stated below:

$$
Q=c m \Delta T
$$

The specific heat capacity is found by using the following formula and known values for the specific heat capacity of water, the stainless steel bucket and air.

$$
\begin{gathered}
C_{C} m_{C} \Delta T_{C}=C_{S} m_{S} \Delta T_{S}+C_{W} m_{W} \Delta T_{W}+ \\
C_{A} m_{A} \Delta T_{A}+\left[M_{W} l\right]
\end{gathered}
$$

where,

$\iota$ is specific latent heat of the water $\left(226 \times 10^{4}\right)$;

$M_{w}$ is mass of water in air (evaporated water).

The values needed to calculate the specific heat capacity using the Eq. (4) can be found in Table 4.

\subsection{Thermal Conductivity}

According to BS EN ISO 8990: 1996 and BS EN 1934: 1998, a method called "hot-box" is developed by Dundee University in order to measure steady-state thermal transmission properties.

This equipment contains two sides: heating side and cooling side. Heating side is achieved by using $40 \mathrm{~W}$ light bulb and cooling side is achieved by using a fridge. Both cold box from cooling side and hot box from heating side needs to be insulated. As well as this, the box which includes the sample is also insulated. This experiment with two sides is designed on a trolley

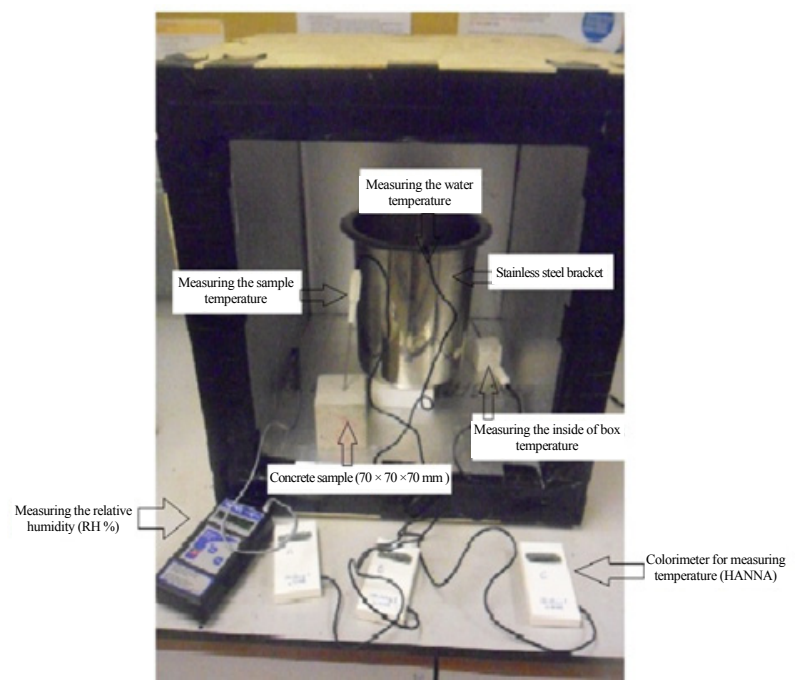

Fig. 1 The apparatus to measure the specific heat capacity of concrete.

Table 4 Known specific heat capacities.

\begin{tabular}{ll}
\hline Material & Specific heat capacity $\left(\mathrm{Jkg}^{-1} \mathrm{~K}^{-1}\right)$ \\
\hline Stainless steel $18 \mathrm{Cr} / 8 \mathrm{Ni}$ & 502 \\
Water at $20{ }^{\circ} \mathrm{C}, 30{ }^{\circ} \mathrm{C}, 40{ }^{\circ} \mathrm{C}$ & $4,181.6,4,178.2,4,178.3$, \\
and $50{ }^{\circ} \mathrm{C}$ & $4,180.4$ \\
Air at $20{ }^{\circ} \mathrm{C}$ to $100{ }^{\circ} \mathrm{C}$ (Dry) & 1,006 \\
\hline
\end{tabular}

where both fridge and cold box is kept fixed, while designing the hot box and sample box in a way to move towards and away from the fixed part of the apparatus. It can be seen in Fig. 2.

$$
\Phi_{p}=\frac{(40 \times \text { counter reading })}{(\text { time between readings })}
$$

By using the heating side of the equipment, total power input $\left(\Phi_{p}\right)$ is calculated by using the measurement obtained from thermostat of hot box and timer counting. Timer counting is used to determine

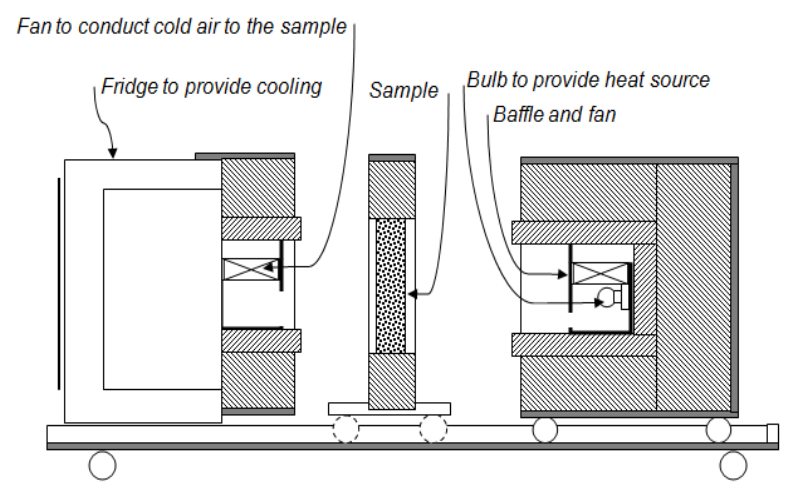

Fig. 2 Schematic of hot box equipment. 
the proportion of the time needed to maintain constant temperature with heat source generated by $40 \mathrm{~W}$ light bulb and a fan that is used to circulate the air.

Insulated box is open at both ends. At one open end, a fan is attached to the fridge whereas on the other open end the sample box is presented. This sample box is designed in a way that can be opened from the top to place the sample inside the sample box.

After the sample is placed, thermocouples are sealed at both sides of the box. Same amount of thermocouples are placed on heating side and cooling side separately. The sample that will be used in this study is square shape slab with $300 \mathrm{~mm}$ length and $75 \mathrm{~mm}$ thickness. Temperature of the sample during the experiment is controlled by using a temperature controller at $240 \mathrm{~V} / 2 \mathrm{~A}$. The voltage and current used in the experiment are recorded by using 16 channel thermocouple data acquisition and a simple logger log system. Hence, thermal conductivity values are calculated by using the equation below:

$$
\lambda=\frac{Q_{1}}{A \times \Delta T} \times d
$$

where,

$$
\begin{gathered}
Q_{1}=Q_{p}-Q_{3}-Q_{4} \\
Q_{4}=\left(0.9763 \times Q_{p}\right)-6.2516
\end{gathered}
$$

$d$ is the thickness of the sample;

$A=0.04 \mathrm{~m}^{2}$ (exposed area);

$\Delta T$ is the temperature difference between the hot side of the equipment and cold side of the equipment and $d=0.075 \mathrm{~m}$ which is the thickness of the samples;

$Q_{P}$ is the total heat input;
$Q_{1}$ is the heat transferred from hot side of the equipment to cold side of the equipment through the specimen;

$Q_{3}$ is the heat loss from hot side of the equipment to the environment;

$Q_{4}$ is the flanking loss that is the heat lost through the gap between the specimen and the equipment during the experiment.

\subsection{Density of Hardened Concrete}

Hardened concrete density is determined either by simple dimensional checks, followed by weighing and calculation, or by weight in air/water buoyancy methods (BSEN 12390-7, 1097-6).

The density of hardened concrete specimens such as cubes and cylinders can be quickly and accurately determined using a Buoyancy Balance.

\section{Experimental Results and Discussions}

The thermal properties of concrete mixes were measured. The values of the measured properties are summarized in Table 5.

Fig. 3 shows the relationship between the thermal conductivity and density of the concrete. OPC with natural coarse aggregate exhibits the highest value on both thermal conductivity and density.

On the other hand, the lowest thermal conductivity and density of concrete occurred at $20 \%$ of PFA replacement for ordinary Portland cement. Additions of admixtures to the concrete affect the thermal

\begin{tabular}{|c|c|c|c|c|c|c|}
\hline \multirow[t]{2}{*}{ Mix No. } & \multirow[t]{2}{*}{ Density $\left(\mathrm{Kg} / \mathrm{m}^{3}\right)$} & \multirow{2}{*}{$\begin{array}{l}\text { Thermal conductivity } \\
(\mathrm{W} / \mathrm{m} \cdot \mathrm{K})\end{array}$} & \multirow{2}{*}{$\begin{array}{l}\text { Specific heat capacity } \\
(\mathrm{J} / \mathrm{Kg} \cdot \mathrm{K})\end{array}$} & \multirow{2}{*}{$\begin{array}{l}\text { Thermal diffusivity } \\
\left(\mathrm{m}^{2} / \mathrm{sec}\right) \times 10^{-7}\end{array}$} & \multicolumn{2}{|c|}{$\begin{array}{l}\text { Compressive strength } \\
\left(\mathrm{N} / \mathrm{mm}^{2}\right)\end{array}$} \\
\hline & & & & & 7 days & 28 days \\
\hline A1 & 2,270 & 0.921 & 785 & 5.2 & 35 & 45 \\
\hline $\mathrm{A} 2$ & 2,255 & 0.880 & 836 & 4.7 & 27 & 42 \\
\hline A6 & 2,220 & 0.820 & 847 & 4.4 & 29 & 41 \\
\hline A8 & 2,265 & 0.902 & 816 & 4.9 & 33 & 44 \\
\hline B1 & 2,150 & 0.720 & 882 & 3.8 & 27 & 39 \\
\hline B2 & 2,135 & 0.670 & 940 & 3.3 & 22 & 42 \\
\hline B6 & 2,120 & 0.610 & 950 & 3.0 & 25 & 41 \\
\hline B8 & 2,140 & 0.690 & 907 & 3.6 & 24 & 42 \\
\hline
\end{tabular}
conductivity and density. Comparing PFA, GGBS and

Table 5 Density, specific heat, thermal diffusivity and thermal conductivity of concrete. 


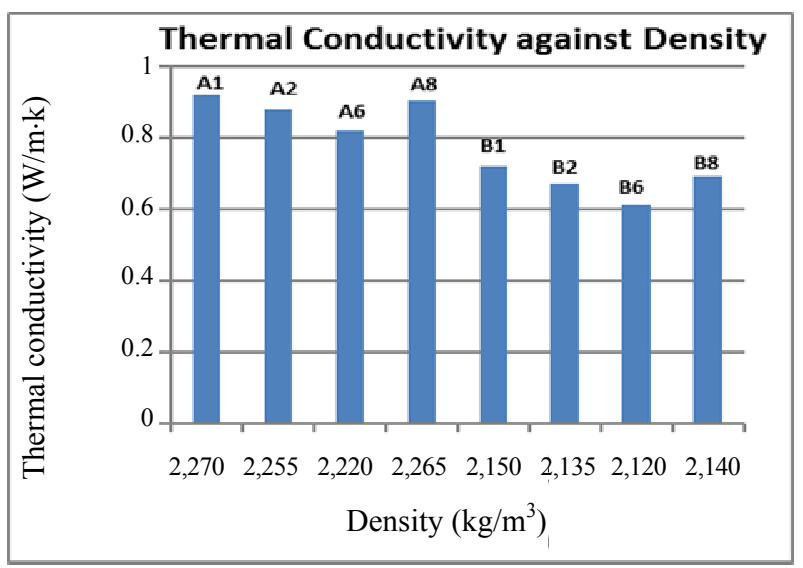

Fig. 3 Thermal conductivity against density graph.

$\mathrm{OPC}, \mathrm{OPC}$ concrete is slightly greater than GBBS and $\mathrm{SF}$ concretes.

On the other hand, recycled coarse aggregate decreased the thermal conductivity and density of the concrete. RCA concretes are the light weight aggregate concretes which have low density. In such cases, there is a lack of information about recycled aggregate concrete and admixtures.

The previous studies reported that the reduction in thermal conductivity is observed with increasing silica fume and PFA contents. This means that SF and PFA are probably related to the higher air content and partly to the amorphous structure of SF and PFA [9-11].

On the other hand, the results are shown that the chemical and physical properties of admixtures are important. For instance, even the amount of PFA in the concrete mix is less than the amount of GBBS, PFA is found to be more effective than SF and GGBS. Ordinary portland cement concrete has the highest thermal conductivity and density (Fig. 4). However, the specific heat capacity of OPC concrete is lower than all of the mixes which are also demonstrated in previous studies in the literature.

This might be due to having low specific gravity of mineral admixtures. In other words, lower specific gravity results in porous and lower density of concrete. Decreasing in density causes a decreasing in thermal conductivity $[9,10]$.

The admixtures increased with increasing specific

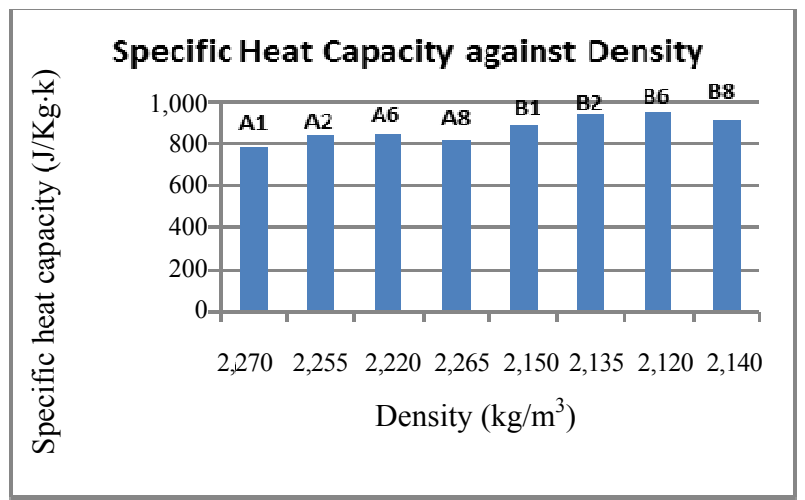

Fig. 4 Specific heat capacity against density graph.

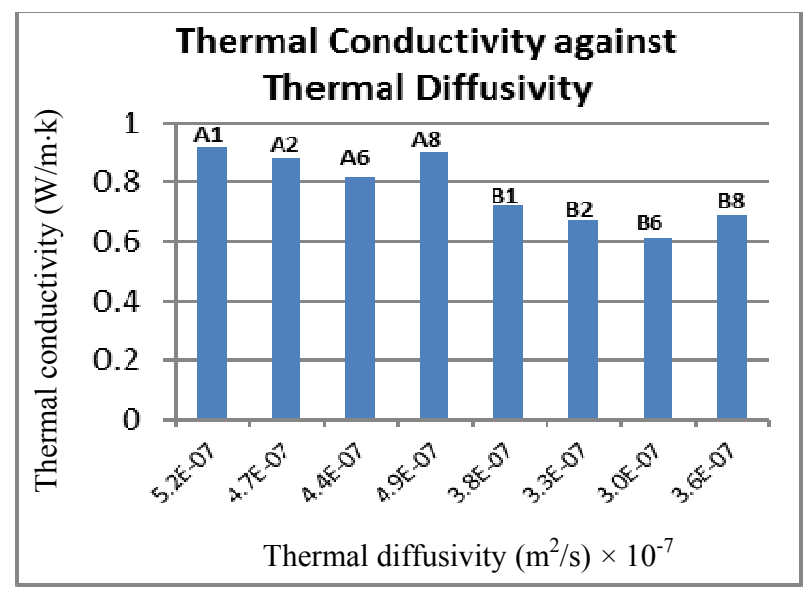

Fig. 5 Thermal conductivity against thermal diffusivity.

heat capacity of concrete. It is observed that OPC concrete is the highest density and the lowest specific heat capacity. On the other hand, the replacement of PFA for OPC is the lowest density and the highest specific heat capacity in natural and RCA concrete mixes (Fig. 4).

Fig. 5 represents that the thermal conductivity is directly proportional with thermal diffusivity. It is observed that both of these parameters are simultaneously increasing.

\section{Thermal Dynamic Calculation}

The excel file is set up to calculate the thermal dynamic properties of concrete mixes by applying the thermal properties data (thermal conductivity, density and specific heat capacity) of the concrete mixes. The main aim of this excel file is to calculate thermal admittance and hence thermal mass. Additionally, 
thermal dynamic properties such as thermal transmittance (U-value) and decrement factor are evaluated.

The main aim of this section is to understand the effects of CRM (cement replacement materials), and recycled coarse aggregate of the concrete mixes on the thermal admittance and other thermal dynamic properties of concrete mixes. Before setting up the excel calculator, the thermal dynamic properties are calculated theoretically. BS EN ISO 13786:2007 standard is used to calculate those parameters [12]. The thickness of the samples is $0.075 \mathrm{~m}$ (constant). The results are provided in Table 6.

Especially PFA content in concrete mixes has the lowest U-value and the highest $\mathrm{R}$-value of the concrete mixes. The highest $U$-value is obtained when cement replacement material is silica fume. However, GGBS content in concrete mixes has greater R-value than silica fume content in concretes. When recycled coarse aggregate content in concrete mixes is examined, it is concluded that RCA content in concrete decreased the U-value more than cement replacement materials of concrete mixes. It is found that thermal conductivity of concrete is increased with increasing the decrement factor value and specific heat capacity of concrete decreased with decreasing the decrement factor of the concrete mixes. Beyond the specific heat capacity of $750 \mathrm{~J} / \mathrm{Kg} \cdot \mathrm{K}$, decrement factor of the concrete mix decreased suddenly. On the other hand, RCA content in concrete decreased the decrement factor of concrete mix. When the specific heat capacity of concrete mix is

Table 6 Thermal dynamic properties of concrete.

\begin{tabular}{lllll}
\hline $\begin{array}{l}\text { Mix } \\
\text { No. }\end{array}$ & $\begin{array}{l}\text { R-Value } \\
\left(\mathrm{m}^{2} \cdot \mathrm{K} / \mathrm{W}\right)\end{array}$ & $\begin{array}{l}\mathrm{U}-\mathrm{W} / \mathrm{m} \cdot \mathrm{K}) \\
(\mathrm{W})\end{array}$ & $\begin{array}{l}\text { Thermal } \\
\text { admittance } \\
\left(\mathrm{W} / \mathrm{m}^{2} \cdot \mathrm{K}\right)\end{array}$ & $\begin{array}{l}\text { Decrement } \\
\text { factor }\end{array}$ \\
\hline A1 & 0.81 & 3.98 & 4.19 & 0.87 \\
A2 & 0.85 & 3.92 & 4.20 & 0.86 \\
A6 & 0.91 & 3.82 & 4.14 & 0.86 \\
$\mathrm{~A} 8$ & 0.83 & 3.95 & 4.20 & 0.87 \\
B1 & 0.104 & 3.65 & 4.03 & 0.86 \\
B2 & 0.112 & 3.55 & 4.03 & 0.85 \\
B6 & 0.123 & 3.41 & 3.96 & 0.84 \\
B8 & 0.109 & 3.59 & 4.02 & 0.85 \\
\hline
\end{tabular}

greater than $850 \mathrm{~J} / \mathrm{Kg} \cdot \mathrm{K}$, decrement factor of the concrete is decreased significantly. However, decreasing in thermal conductivity of concrete mixes is also observed.

On the other hand, when GGBS is used in concrete mix, it increases the thermal admittance more than all groups. PFA content in concrete mixes has the lowest thermal admittance value in all mixes. Silica fume concretes has similar value of thermal admittance with ordinary Portland cement concrete mixes. RCA content in concrete mixes have the lowest thermal admittance values than other natural aggregate content in concrete mixes.

\section{Conclusions}

Laboratory experiments are carried out to determine the thermal properties of the concrete namely, thermal conductivity, specific heat capacity and density. Results obtained from these tests are used to make inferences on how each of the thermal properties affect the thermal admittance and hence the thermal mass of the concrete. Main findings are reported as follows.

The obtained results proved that cement replacement affected the density and thermal conductivity of the concrete. For instance, when the cement is replaced by PFA, it is found to decrease the thermal conductivity in a direct proportional manner and thermal diffusivity of the concrete. As well as this, all cement replacement materials are increased with increasing the specific heat capacity of the concrete. The results also show that CRM content is important in considering the effect of thermal properties of the concrete. However, the chemical and physical properties of the material are more important than the amount of material in the concrete such as PFA. Thermal properties are also affected by the types of aggregate. In this research, natural aggregate is replaced by recycled coarse aggregate. The results are described that RCA content affect the thermal properties of concrete. RCA content increased with decreasing the density, thermal conductivity and thermal diffusivity of the concrete. 
On the other hand, RCA content increased with increasing of the specific heat capacity of concrete. The laboratory tests show that RCA content decreased the density and thermal conductivity of concrete more than CRM content. Beside of this, when RCA and admixture content increased in the concrete mix, this increases the specific heat capacity of the concrete.

It is concluded that cement replacement materials increase the R-value with decreasing $\mathrm{U}$-value of the concrete mixes less than RCA content concretes. The obtained results explain that when cement replacement materials are compared in terms of decrement factor value, no significant difference is found between the mixes.

When the value of thermal admittance is concerned, it is found that this value does not need to have high or low thermal conductivity of concrete mix. The importance is to have a moderate thermal conductivity. The results are provided that thermal admittance is increased with high specific heat capacity, high density and moderate thermal conductivity of the concrete mixes. Therefore, those factors are found to be vital to obtain the optimal level of thermal mass of concrete mix.

\section{References}

[1] Thermal Mass for Housing, TCC/04/05, The Concrete Centre, 2006

[2] Arup/Bill Dunster architects, UK Housing and Climate Change Heavyweight versus Lightweight Construction,
Arup Research + Development, Bill Dunster Architects, UK, 2004.

[3] P. Barton, C.B. Beegs, P.A. Sleigh, A theoretical study of the thermal performance of the thermodeck hollow core slab system, Applied Thermal Engineering 22 (2002) 1485-1499.

[4] CIBSE Guide A Environmental Design, The Chartered Institution of Building Services Engineers, London, 1999.

[5] CIBSE Guide, Thermal Properties of Building Structures (A3), The Chartered Institution of Buildings Services, London, 1980.

[6] CIBS Guide, Summertime Temperatures in Buildings (A8), The Chartered Institution of Buildings Services, London, 1975.

[7] Climate Change and the Indoor Environment: Impacts and Adaptation, TM36, CIBSE, Ascot, CIBSE (Chartered Institute of Building Services Engineers), UK, 2005.

[8] B. Milovanovic, P.I. Banjad, I. Gabrijel, Measuring thermal properties of hydrating cement pastes, in: $31 \mathrm{st}$ Cement and Concrete Science Conference, Novel Developments and Innovation in Cementitious Materials, Imperial College London, United Kingdom, 2011.

[9] H. Asan, Y.S. Sancaktar, Effects of walls's thermophysical properties on time lag and decrement factor, Energy and Building 28 (1998) 159-166.

[10] X. Fu, D.D.L. Chung, Effect of admixtures on thermal and thermo-mechanical behavior of cement paste, ACI Mater J. 96 (4) (1999) 455-461.

[11] Y. Xu, D.D.L. Chung, Cement of High Specific Heat and High Thermal Conductivity, Obtained by Using Silane and Silica Fume as Admixtures, Cement and Concrete Research 30 (2000) 1175-1178.

[12] EN ISO 13786:2007, Thermal Performance of Building Components-Dynamic Thermal CharacteristicsCalculation Methods International Organization for Standardization, 2007. 